\title{
Multi-modal imaging of high-risk ductal carcinoma in situ of the breast using C2Am: a targeted cell death imaging agent
}

\author{
Zoltan Szucs', James Joseph ${ }^{1,2,3}$, Tim J. Larkin ${ }^{1}$, Bangwen Xie', Sarah E. Bohndiek ${ }^{1,2}$, Kevin M. Brindle ${ }^{1,4^{*}}$ and
} André A. Neves ${ }^{1 *}$ (D)

\begin{abstract}
Background: Ductal carcinoma in situ (DCIS) is a non-invasive form of early breast cancer, with a poorly understood natural history of invasive transformation. Necrosis is a well-recognized adverse prognostic feature of DCIS, and non-invasive detection of its presence and spatial extent could provide information not obtainable by biopsy. We describe here imaging of the distribution and extent of comedo-type necrosis in a model of human DCIS using C2Am, an imaging agent that binds to the phosphatidylserine exposed by necrotic cells.

Methods: We used an established xenograft model of human DCIS that mimics the histopathological features of the disease. Planar near-infrared and optoacoustic imaging, using fluorescently labeled C2Am, were used to image non-invasively the presence and extent of lesion necrosis.

Results: C2Am showed specific and sensitive binding to necrotic areas in DCIS tissue, detectable both in vivo and ex vivo. The imaging signal generated in vivo using near-infrared (NIR) fluorescence imaging was up to 6-fold higher in DCIS lesions than in surrounding fat pad or skin tissue. There was a correlation between the C2Am NIR fluorescence (Pearson $R=0.783, P=0.0125)$ and optoacoustic signals $(R>0.875, P<0.022)$ in the DCIS lesions in vivo and the corresponding levels of cell death detected histologically.

Conclusions: C2Am is a targeted multi-modal imaging agent that could complement current anatomical imaging methods for detecting DCIS. Imaging the presence and spatial extent of necrosis may give better prognostic information than that obtained by biopsy alone.
\end{abstract}

Keywords: DCIS, Multi-modal imaging, Optoacoustic, Necrosis, Early detection

\section{Introduction}

Breast cancer is the most commonly diagnosed malignancy in women in the Western world, affecting one in eight women during their lifetime, with approximately $20 \%$ of newly diagnosed cases being DCIS [1]. The introduction of mammographic screening programs in the 1980 s led to an estimated $40 \%$ reduction in breast

\footnotetext{
*Correspondence: kmb1001@cam.ac.uk; andre.neves@cruk.cam.ac.uk ${ }^{1}$ Cancer Research UK Cambridge Institute, Li Ka Shing Centre, University of Cambridge, Robinson Way, Cambridge CB2 ORE, UK

Full list of author information is available at the end of the article
}

cancer-related mortality. However, diagnosis of biologically indolent breast cancer, which might not otherwise become clinically apparent during the lifetime of the patient [2], has led to an estimated overdiagnosis of $10 \%$ of cases, mainly attributed to the sevenfold increase in the detection rates of DCIS [3].

DCIS is a non-obligate precursor of invasive breast cancer, representing a pathologically heterogeneous group of neoplastic processes in situ, with differing growth rates, a range of microarchitectural and cytological patterns, and diverse malignant potential, with an

(c) The Author(s). 2021, corrected publication 2021. Open Access This article is licensed under a Creative Commons Attribution 4.0 International License, which permits use, sharing, adaptation, distribution and reproduction in any medium or format, as long as you give appropriate credit to the original author(s) and the source, provide a link to the Creative Commons licence, and indicate if changes were made. The images or other third party material in this article are included in the article's Creative Commons licence, unless indicated otherwise in a credit line to the material. If material is not included in the article's Creative Commons licence and your intended use is not permitted by statutory regulation or exceeds the permitted use, you will need to obtain permission directly from the copyright holder. To view a copy of this licence, visit http://creativecommons.org/ licenses/by/4.0/. The Creative Commons Public Domain Dedication waiver (http://creativecommons.org/publicdomain/zero/1. 0/) applies to the data made available in this article, unless otherwise stated in a credit line to the data. 
unpredictable transition time to invasive cancer [3]. Surgical excision is mandatory in the clinical management of DCIS [4], and while mastectomy offers higher cure rates, due to its mutilating nature, this has been mostly replaced by breast-conserving surgery (BCS) [5]. There is a major clinical concern that the standard-of-care treatment of DCIS might be unnecessarily aggressive for patients with lesions deemed as "low risk" [6, 7].

The presence of comedo-type necrosis at diagnosis is associated with an increased risk of local recurrence, when BCS is used [8]. Both the presence and the extent of necrosis within DCIS lesions have been shown, in a sub-analysis of a large international randomized clinical trial, to have a significant association with the rates of both non-invasive and invasive local recurrences [9], particularly for high-grade lesions [10]. This trial showed that not only the presence, but also the anatomical extent of comedo-necrosis holds relevant prognostic information [9]. In a recent study, the presence of necrosis in diagnostic preoperative biopsies of over 600 women with DCIS was found to be a strong predictor of both DCIS upgrading and upstaging to invasive carcinoma in the final surgical specimens [11].

Reliable detection of comedo-type necrosis in biopsy specimens poses a challenge as it is based on a subjective assessment and is therefore highly variable [12]. At present, only post-surgical histological evaluation of breast resection specimens (lumpectomy or mastectomy) can reliably determine the actual extent of comedo-type necrosis. Pre-surgical diagnostic biopsy of suspect DCIS lesions can only inform on the presence or absence of this high-risk feature in the spatially limited biopsy specimen, thus providing potentially incomplete prognostic information.

The development of novel imaging tools that can predict prognosis in DCIS more effectively is an unmet clinical need [7]. Current imaging techniques do not provide prognostic information beyond anatomical estimates of lesion size, which often lack accuracy when delineating the extent of DCIS involvement. In the last two decades, magnetic resonance imaging (MRI) has emerged as a potential adjunct to mammography, despite the additional cost [13]. However, a meta-analysis concluded that routine use of preoperative MRI, in addition to conventional preoperative assessment of patients with newly diagnosed DCIS, was not associated with improved surgical outcomes [14-16]. Recently, the fast hybrid optical and acoustic technology of optoacoustic (OA) imaging has emerged as a promising diagnostic tool for the evaluation of breast lesions $[17,18]$. To date, the reported OA trials have focused on imaging tumor hemoglobin concentration and oxygenation. While these metrics have been shown to correlate with tumor necrosis [19], they do not provide a specific readout of the process. Non- invasive imaging modalities that can reliably detect and potentially quantify and map comedo-type necrosis would be a useful adjunct to mammography.

$\mathrm{C} 2 \mathrm{Am}$ is a modified version of the C2A domain of Synaptotagmin-I, in which a single-cysteine residue, introduced by site-directed mutagenesis, can be used for selective labeling of the protein with labels detectable using non-invasive imaging techniques [20]. This small protein $(16 \mathrm{kDa})$ can detect, with low nanomolar affinity, the phosphatidylserine (PS) externalized to the outer leaflet of the plasma membrane, during apoptosis, and which becomes accessible on the inner leaflet of necrotic cells, following the plasma membrane disruption that accompanies necrosis [21]. C2Am can detect tumor cell death following treatment, using fluorescence, optoacoustic [22], SPECT [23], and more recently, PET [24] imaging in vivo. We show here that we can use a fluorophore-labeled derivative of C2Am for multi-modal detection of comedo-type necrosis with fluorescence and optoacoustic imaging in an established human-in-mouse intraductal transplantation model of DCIS, which has been shown to model accurately human high-risk DCIS [25].

\section{Materials and methods Cell culture}

All chemicals were obtained from Sigma-Aldrich unless stated otherwise. MCF10ADCIS.com cells (CVCL_5552, Asterand, Inc. Detroit, MI) [26, 27] were stably transfected with firefly luciferase and RFP [28] (herein named MCF10A $\left._{\mathrm{DCIS}}\right)$, cultured in DMEM/F12 (1:1) medium supplemented with $5 \%$ horse serum (Thermo Fisher Scientific) and $4 \mathrm{mM}$ glutamine, in a $37^{\circ} \mathrm{C}$ humidified incubator with an atmosphere of $5 \% \mathrm{CO}_{2}$. The cell line, which tested negative for mycoplasma by an RNA capture ELISA-based method, was genotyped upon arrival and used within 4 to 8 passages from the original stocks. An automated cell viability analyzer (Vi-Cell ${ }^{\mathrm{Tw}}$, Beckman Coulter) was used to monitor cell number and viability. Where required, cell death was induced by incubating cells with $10 \mu \mathrm{M}$ doxorubicin or $100 \mu \mathrm{M}$ etoposide (Teva, Ltd.) for $24 \mathrm{~h}$ at $37^{\circ} \mathrm{C}$.

\section{C2Am and iC2Am expression and labeling}

For fluorescence and optoacoustic imaging, C2Am and a site-directed mutant of the protein that no longer binds to PS (iC2Am) [20] were expressed in E. coli BL21, previously transformed with pGEX-2T vector containing either GST-C2Am or GST-iC2Am [20], purified and labeled using either DyLight ${ }^{\mathrm{tm}}$-650-maleimide (Thermo Fisher Scientific, $\left.E_{x} / E_{m}=654 / 673 \mathrm{~nm}\right)$ for $\mathrm{iC} 2 \mathrm{Am}$ or AlexaFluor $^{\text {Ta }}$-750-C5-maleimide (Life Sciences, $E_{x} / E_{m}=$ $750 / 775 \mathrm{~nm}$ ) for C2Am. The bioconjugation protocol has been described previously [20]. 


\section{DCIS intraductal murine model}

Sub-confluent MCF10A $A_{\text {DCIS }}$ cells (>95\% viability) were washed and re-suspended at $5 \times 10^{3}$ cells $/ \mathrm{mL}$, in chilled medium containing 65\% DMEM/F12 (1:1), 5\% horse serum, and 20\% growth factor-reduced Matrigel (BD Biosciences). The cell suspension was delivered intraductally to recipient 8-12-week-old female NOD/SCIDIL2 $R_{\text {gamma }}$ mice (Jackson Laboratories), under isoflurane (1-3\%) anesthesia, using a method described previously [25]. All animal experiments were performed in compliance with a project license issued under the Animals (Scientific Procedures) Act of 1986 and were designed with reference to the UK Co-ordinating Committee on Cancer Research guidelines for the welfare of animals in experimental neoplasia [29]. Protocols were approved by the Cancer Research UK Cambridge Institute Animal Welfare and Ethical Review Body.

\section{Planar epifluorescence (FLI) and bioluminescence (BLI) imaging}

$\mathrm{C} 2 \mathrm{Am}$ and iC2Am were administered as an equimolar mixture of $0.10 \mu \mathrm{mol} / \mathrm{kg}$ for each of the two probes $(10$ $\mathrm{mL} / \mathrm{kg}$, i.v.). Imaging in vivo and ex vivo was performed using an IVIS200 ${ }^{\text {mi }}$ system (Perkin Elmer). BLI was conducted 5-10 min following administration of D-luciferin (Perkin Elmer, $150 \mathrm{mg} / \mathrm{kg}$, i.p. in phosphate-buffered saline). FLI and BLI were performed under $2-3 \%$ isoflurane gas anesthesia mixed with $100 \%$ oxygen. Body temperature was maintained at $37^{\circ} \mathrm{C}$. The in-plane resolution was $100 \mu \mathrm{m}$.

\section{Optoacoustic imaging}

C2Am (C2Am-AF750) and iC2Am (iC2Am-DyL650) were administered as an equimolar mixture of $0.20 \mu \mathrm{mol} / \mathrm{kg}$ (10 mL/kg, i.v.). Optoacoustic (OA) imaging in vivo was performed using a multispectral optoacoustic tomography $\left(\mathrm{MSOT}^{\mathrm{mm}}\right)$ inVision 256-TF small animal imaging system (iThera Medical) [30]. Briefly, a tunable optical parametric oscillator (OPO) pumped by a Nd:YAG laser provided excitation pulses with a pulse width $<7 \mathrm{~ns}$ at wavelengths ranging from 660 to 1300 $\mathrm{nm}$ at a repetition rate of $10 \mathrm{~Hz}$, wavelength tuning speed of $10 \mathrm{~ms}$, and peak pulse energy of $90 \mathrm{~mJ}$ at 720 $\mathrm{nm}$. Ten arms of a fiber bundle provided uniform illumination of a ring-shaped light strip of approximately 8 $\mathrm{mm}$ width, with radiant exposure of $<20 \mathrm{~mJ} / \mathrm{cm}^{2}$ (maximum permissible exposure) on the sample surface. For ultrasound detection, 256 toroidally focused ultrasound transducers, with a center frequency of $5 \mathrm{MHz}(60 \%$ bandwidth) and organized in a concave array with $270^{\circ}$ angular coverage and a radius of curvature of $4 \mathrm{~cm}$, were used [31]. Anesthetized animals were wrapped in a thin polyethylene membrane and placed in the animal holder. The animal holder was held within the imaging chamber at a constant temperature $\left(36^{\circ} \mathrm{C}\right)$, maintained by heating degassed $\mathrm{D}_{2} \mathrm{O}$. The mice were allowed to temperature stabilize for $12 \mathrm{~min}$ within the imaging chamber before any scans were performed. The respiratory rate of the animals was maintained (70-80 b.p.m.) by modulating the isoflurane concentration $(1.5-2.5 \%$ isoflurane concentration). OA data were acquired from multiple cross-sectional slices with 10 frame averages. The OA responses of $\mathrm{iC} 2 \mathrm{Am}$ and $\mathrm{C} 2 \mathrm{Am}$ were evaluated using phantoms (Supplementary Figure S2).

\section{Immunohistochemistry and tissue fluorescence imaging ex vivo}

Tissues were fixed for $24 \mathrm{~h}$, using neutral-buffered formalin, prior to transfer into $70 \%$ ethanol. The sections $(3 \mu \mathrm{m})$ were cut using a rotary microtome. Hematoxylin and eosin (H\&E) staining was performed on a Leica ST5020/CV5030 workstation (Leica Biosystems). Cleaved-caspase-3 (CC3) and TUNEL staining were performed as described previously [32]. Unstained tissue sections were de-waxed and rehydrated and the slides mounted using Prolong Gold ${ }^{\mathrm{m}}$ antifade reagent (Thermo Fisher Scientific), cured for $24 \mathrm{~h}$ at room temperature, prior to microscopic near-infrared fluorescence (NIRF) imaging at a resolution of $21 \mu \mathrm{m}$, using an Odyssey ${ }^{\mathrm{max}} 250$ flat-bed scanner (LiCor Inc.).

\section{Statistical analysis}

Data are shown as mean \pm SD, unless stated otherwise. A two-tailed Student's $t$ test was used for pairwise comparisons. ANOVA was used for multiple comparisons. Pearson's $R$ test was used to assess the significance of the correlations. $P$ values of $<0.05$ were considered significant. Statistical analyses were performed in GraphPad Prism $^{\text {Th }}$ (GraphPad Software, vs. 6.0).

\section{Results}

The potential of MCF10A $\mathrm{DCIS}_{\mathrm{D}}$ cells to form DCIS-like lesions was assessed at different time points $(2,5$, and 8 weeks, $n=10$; Table 1) following intraductal implantation [33]. All lesions, manually identified at each time point, exhibited high-grade cytonuclear features, as determined by hematoxylin and eosin (H\&E) staining (Fig. 1c-e). The DCIS lesion cells contained pleomorphic, irregularly spaced, and large nuclei, exhibiting marked variation in size, with irregular contours, coarse chromatin, and prominent nucleoli. The co-existence of specific architectural DCIS subtypes (solid, cribriform, comedo) and invasive carcinoma within each lesion was assessed. At 2 weeks following implantation, cells in DCIS lesions showed discreet intraductal growth, with no evidence of necrosis (Fig. 1a). Parallel staining, using antibodies against a mouse or human proliferation marker (Ki-67, 
Table 1 Morphological features of MCF10A xenograft lesions

\begin{tabular}{llll}
\hline Cohort & A & B & C \\
\hline Time of tissue harvest post-implantation (weeks) & 2 & 5 & 8 \\
Number of fat pads injected ( $N$ ) & 4 & 6 & 10 \\
Histologically confirmed DCIS/fat pads examined & $2 / 4$ & $6 / 6$ & $10 / 10$ \\
Tissue architecture of DCIS lesions & & & \\
$\quad$ Solid & $2 / 2$ & $4 / 6$ & $2 / 6$ \\
Cribriform & $0 / 2$ & $3 / 6$ & $2 / 6$ \\
Comedo & $0 / 2$ & $2 / 6$ & $6 / 6$ \\
Mixed DCIS (at least two types/specimen) & $0 / 2$ & $4 / 6$ & $2 / 6$ \\
Associated invasive carcinoma & $0 / 2$ & $2 / 6$ & $4 / 6$ \\
\hline
\end{tabular}

$n=10$ mice, 18 lesions

brown), and nuclear staining (DAPI, blue) allowed the identification of human cells within the mouse mammary ducts (Fig. 1a). Staining of human centromeres (Fig. 1b, red) confirmed the extrinsic nature of the malignant cell proliferation. Lesions collected at later time points (5 and 8 weeks following implantation) showed a wider range of DCIS-specific morphological features, which resembled those of the human disease (Fig. 1c, d), including cribriform (Fig. 1c), solid, and comedo-type (Fig. 1d) lesions, which coexisted within the same specimen. While 5-week lesions showed incipient comedo-type necrosis in some (2 in 6) of the xenografts (Table 1), more mature lesions contained a larger number of comedo-type DCIS ducts in all of the material collected (10 out of 10 , Table 1 ). These comedo-type lesions consisted of tightly packed tubular structures with central coagulative necrosis. Closer examination of $\mathrm{H} \& \mathrm{E}$-stained sections (Fig. 1c) revealed a discreet basal myoepithelial layer at the periphery of the duct-like structures. Invasive areas developed in most of the older lesions (Fig. 1e, arrows; Table 1). Comedo-type necrosis was evident on H\&E staining (Fig. 1e, arrowheads) and was identified by the presence of cell ghosts and its eosinophilic and granular nature. Additional TUNEL staining detected necrotic cell debris (Fig. 1f, brown).

We assessed MCF10A $A_{\text {DCIS }}$ cell death in vitro in order to establish the capability of $\mathrm{C} 2 \mathrm{Am}$ to detect cell death in this cell line following treatment. Cells were treated with either doxorubicin or etoposide and cell death was assessed (Fig. 2) using either an equimolar mixture of active $\mathrm{C} 2 \mathrm{Am}$ and a site-directed mutant that does not bind PS (iC2Am) [20] or a fluorescent inhibitor of effector caspases (FLICA [34]). The combined use of C2Am and iC2Am, which were labeled with two different fluorophores, enabled a ratiometric assessment of cell death that accounted for non-specific probe retention by the cells (see Supplementary Figure S1). The

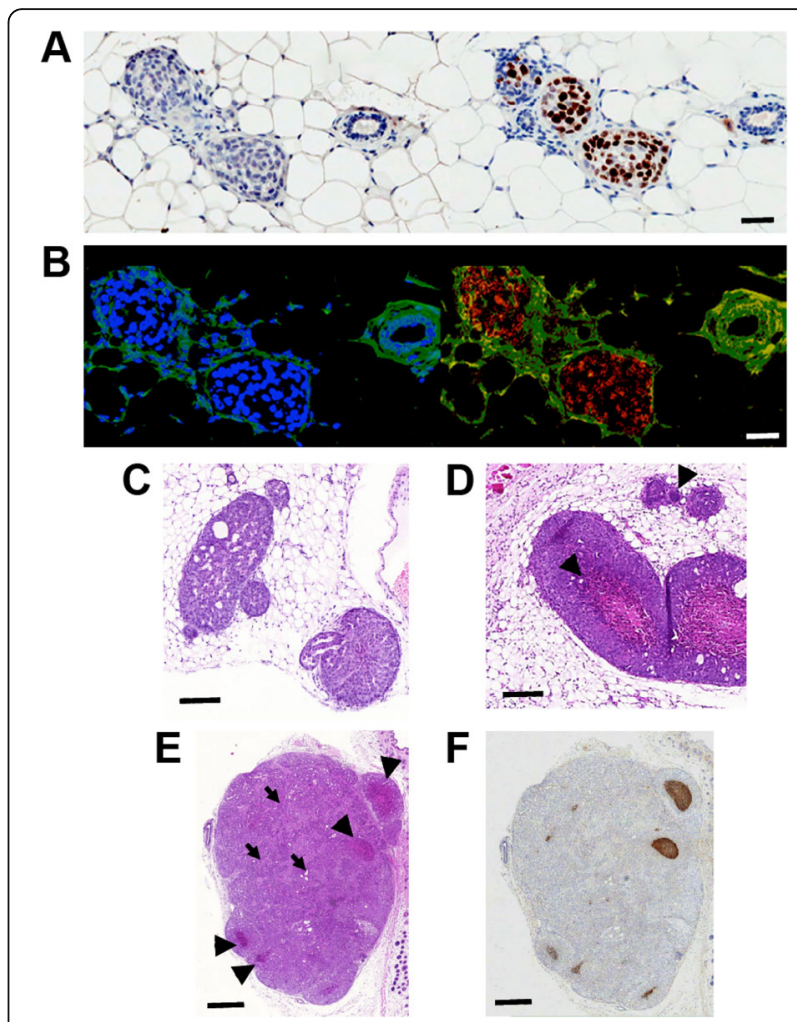

Fig. 1 Histopathological evaluation of an intraductally transplanted model of DCIS (MCF10A solid-type intraductal growth of MCF10A staining with an antibody targeted at mouse Ki- 67 but positive staining with an antibody targeted th the human protein (a, brown stain). DAPI staining (a, $\mathbf{b}$, blue) identified both human and mouse epithelial cells whereas a FISH probe for human centromeres (b, red) identified cells of human origin on an autofluorescent (green) tissue background. Histopathology of DCIS lesions 8 weeks postimplantation (c, d); cribriform architecture of a MCF10A (c); comedo-type necrosis in a MCF10A DCIS xenograft lesion (d, arrowheads), with central necrotic areas. Comedo-necrosis type features of MCF $10 A_{D C I S}$ xenografts 8 weeks post-implantation $(\mathbf{e}, \mathbf{f})$; comedo-type DCIS-like (e, arrowheads) and invasive (e, arrows) structures on H\&E; corresponding TUNEL staining ( $\mathbf{f}$ ), showing viable (gray) and necrotic (brown) regions of tissue. Scale bars $=200 \mu \mathrm{m}(\mathbf{a}$, b); $350 \mu \mathrm{m}$ (c, d); $800 \mu \mathrm{m}(\mathbf{e}, \mathbf{f})$

level of MCF10A $\mathrm{ACIS}_{\mathrm{D}}$ cell death induced by doxorubicin (10 $\mu \mathrm{M}, 24 \mathrm{~h}$, Fig. $2 \mathrm{~b}$, triangles) was higher than that generated by etoposide $(100 \mu \mathrm{M}, 24 \mathrm{~h}$, Fig. $2 \mathrm{~b}$, filled circles), as determined by FLICA staining (Fig. 2a, right). iC2Am generated low levels of fluorescence (Fig. 2a, green), which did not correlate $(R=0.124, P=0.7)$ with caspase-3 activation (Fig. 2b). C2Am, however, showed increased fluorescence with increasing levels of cell death (Fig. 2a, red), which correlated with the levels of FLICA staining (Fig. 2c; $R=0.883, P=0.0001$ ). The $\mathrm{C} 2 \mathrm{Am} / \mathrm{iC} 2 \mathrm{Am}$ ratio also correlated with FLICA staining $(R=0.857, P=0.0004)$, with a level of contrast that 


\section{A}

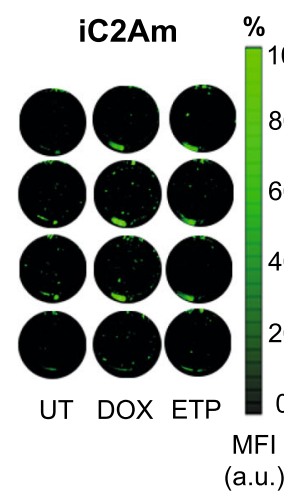

B

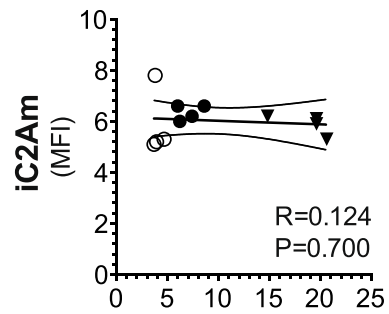

C2Am

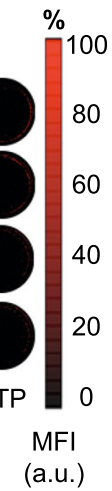

C

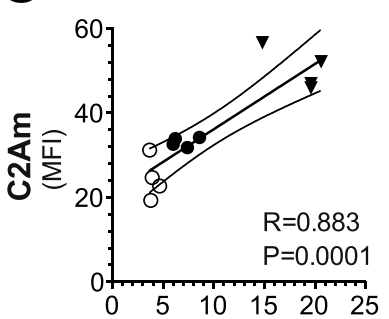

C2Am/iC2Am

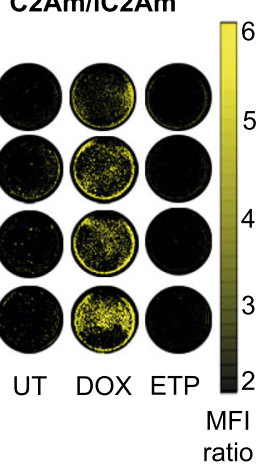

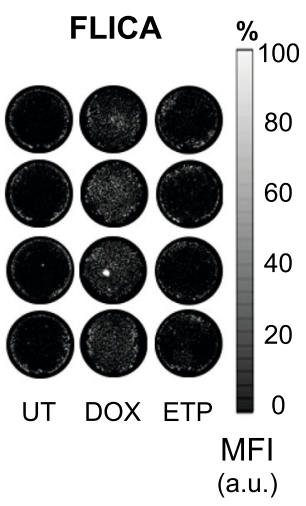

D

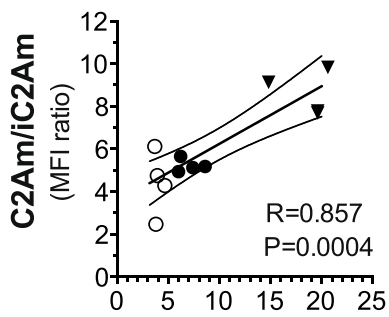

FLICA (MFI)

Fig. 2 Detection of MCF10A incubated with either an equimolar mixture of C2Am|iC2Am or with a fluorescent inhibitor of effector caspases (FLICA) as a reference gold standard. Plates (a) were scanned at different excitation/emission wavelengths: iC2Am (650/680 nm), C2Am (780/800 nm), and FLICA (450/480 $\mathrm{nm}$ ). Correlations of iC2Am staining (b), C2Am staining (c), and the ratio C2Am/iC2Am (d) with FLICA staining. UT-untreated (open circles), DOXdoxorubicin (inverted triangles), and ETP-etoposide-treated (filled circles) cells. C2Am and iC2Am were labeled with DyLigh-750 and AlexaFluor650, respectively (see Supplementary Figure S1 and Methods). FLICA-fluorescent inhibitor of effector caspases. $n=4$ technical replicates per experimental condition, 2 independent experiments

was up to 10 -fold higher with C2Am than with iC2Am (Fig. 2d).

Next, 4 to 8 weeks post-implantation of MCF10A orthotopic lesions $(n=10)$, an equimolar mixture of $\mathrm{C} 2 \mathrm{Am}$ and iC2Am was injected (i.v.) and planar epifluorescence (FLI) and bioluminescence (BLI) images were acquired at $24 \mathrm{~h}$ post-probe administration (Fig. 3A-C). Representative images acquired in vivo (Fig. $3 \mathrm{~A} 1-\mathrm{C} 1$ ) and ex vivo (Fig. 3A2-C2 and A3-C3) are shown. The larger $(\sim 7 \mathrm{~mm})$ inguinal lesion detected by BLI (Fig. 3A1, left arrow), was visible in vivo using C2Am (Fig. 3C1, arrow) but not with iC2Am (Fig. 3B1, arrow), despite the fluorescence of the two probes being equivalent (Supplementary Figure S1). Both inguinal lesions (Fig. 3A1, arrows, BLI) were visible ex vivo using C2Am (Fig. 3C2, arrows) but not with iC2Am (Fig. 3B2, arrows). C2Am fluorescence-guided resection of the larger lesion (Fig. 3C1, left arrow and C3, left) showed ca. 3-fold greater (lesion/fat pad) contrast ex vivo with C2Am than with iC2Am (Fig. 3F, red symbols). Overall, lesions showed significantly higher levels (ca. 7-fold, $P<$
0.005) of fluorescence in vivo (Fig. 3D) with C2Am than with iC2Am. The relative increase in C2Am fluorescence in vivo in fat pad tissue was also significantly higher, in comparison with $\mathrm{iC} 2 \mathrm{Am}$, albeit the contrast was much lower than that observed for lesion tissue (Fig. 3E, ca. 1.5-fold, $P<0.005)$. The lesion-to-fat pad contrast in vivo was also ca. 3 -fold higher (Fig. 3F, $P<0.005$,), using the active $\mathrm{C} 2 \mathrm{Am}$ probe. Moreover, the ratiometric (C2Am/iC2Am) assessment of cell death in vivo correlated (Fig. 3G, $R=0.783, P=0.0125$ ) with the assessment of lesion cell death ex vivo using the TUNEL staining assay. Subsequent histochemical assessment of excised lesion sections (Fig. 4) showed good co-localization of the ratiometric $\mathrm{C} 2 \mathrm{Am} / \mathrm{iC} 2 \mathrm{Am}$ signal (Fig. 4c) with lesion cell death detected by TUNEL staining (Fig. 4b), for the two lesions present in this mouse (Fig. 3A1).

Next, we analyzed multiple excised lesion sections from a cohort of animals $(n=10), 4$ to 8 weeks following

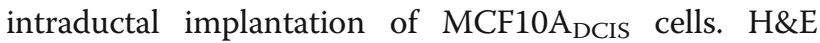
staining (Fig. 5a, top left) of representative lesions showed clear ductal lesion structures (L) embedded in 

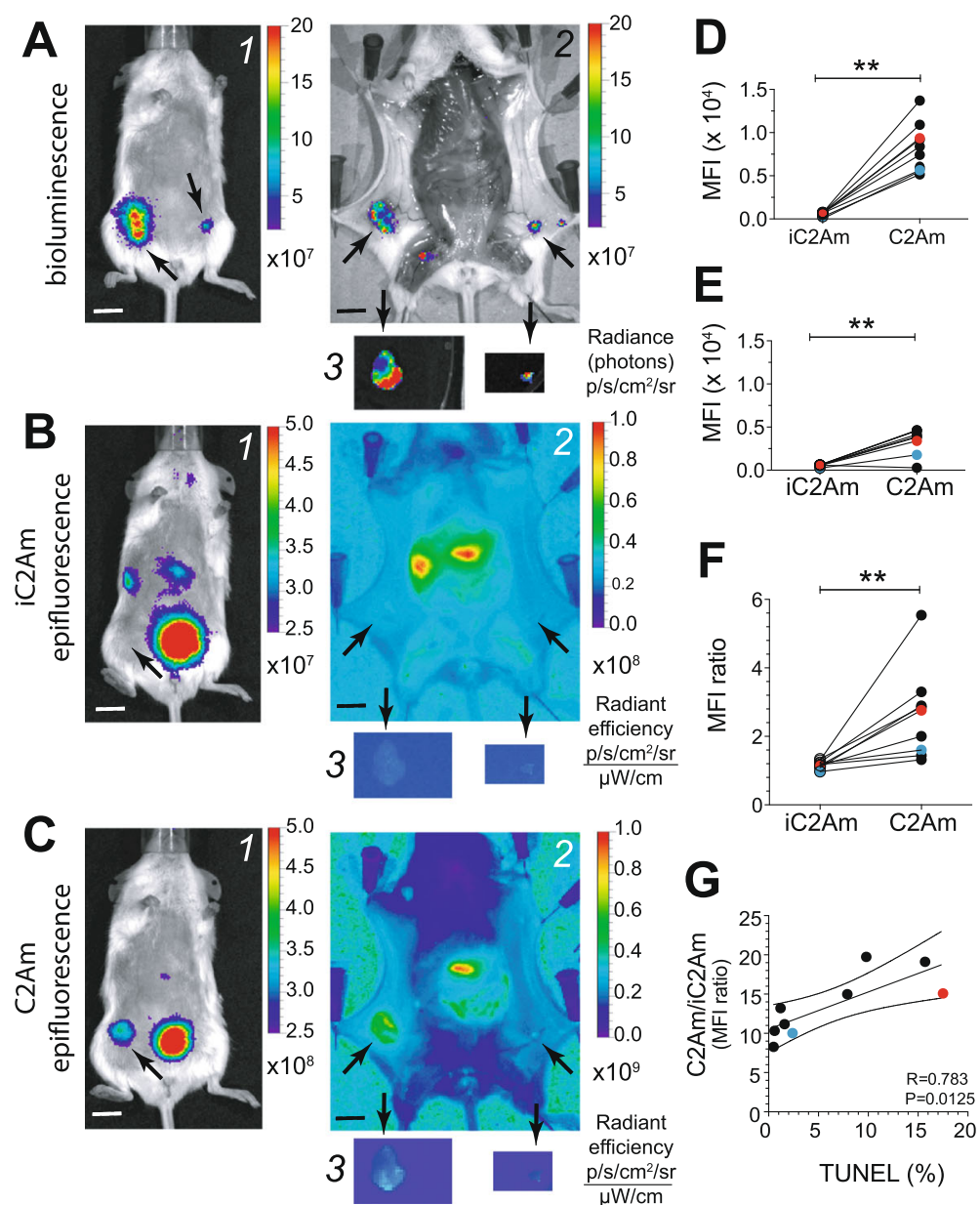

Fig. 3 Fluorescence imaging of native cell death in the MCF10A (FLI; B, C) of a representative mouse implanted intraductally with MCF10A visible in vivo by BLI (A) and the larger lesion by FLI of C2Am in vivo (C1, arrow) and both lesions ex vivo (C2, arrows), but neither were visible by FLI of iC2Am in vivo (B1, arrow) or easily distinguishable ex vivo (B2, arrows). Lesion (D), fat pad (E), and lesion/fat pad ratios (F) of mean fluorescence intensity (MFI) were calculated for C2Am and iC2Am. The C2Am/iC2Am MFI ratio was also calculated for lesions and correlated with the levels of cell death, quantified by TUNEL staining of excised lesion sections (G). The images ex vivo (A-C: $\mathbf{2}, \mathbf{3})$ show the two lesions in situ in the mouse (A2, B2, C2 arrows) and the same lesions post-resection $(\mathbf{A} 3, \mathbf{B} 3, \mathbf{C} 3)$ on a plate. Wilcoxon matched-pair analysis, red and blue dots (D-G) correspond to imaging data shown in $(\mathbf{A}-\mathbf{C})$, for left-side (red) and right-side (blue) lesions. ${ }^{* *} P<0.005$ (D-F). $n=5$ mice, 9 lesions

fat pad tissue (fp) and surrounded by skin (sk). Within these lesions, there were areas with variable cell proliferation (Fig. 5a, Ki-67-stained). Defined, punctate areas of necrosis visible in the lesions (Fig. 5a, H\&E) were also detected by cleaved caspase- 3 (Fig. $5 a$, CC3) and TUNEL (Fig. 5a, TUNEL) staining. In regions of interest (ROI) within these lesions, the ratiometric $\mathrm{C} 2 \mathrm{Am} / \mathrm{iC} 2 \mathrm{Am}$ signal showed a strong correlation $(R=0.717, P=0.0012)$ with TUNEL staining (Fig. 5a, ROI analysis). A correlation was also found between the ratiometric C2Am/ iC2Am signal and TUNEL staining for a large panel of lesions (Fig. 5b, lesion) but not for fat pad (Fig. 5b, fat pad) or skin (Fig. 5b, skin). The contrast obtained with the ratiometric $\mathrm{C} 2 \mathrm{Am} / \mathrm{iC} 2 \mathrm{Am}$ signal (Fig. $5 \mathrm{c}$, left) was also significantly greater for lesions, in comparison with surrounding fat pad (30-fold, $P<0.0001)$ and skin $(15-$ fold, $P<0.0001$ ), and increased in proportion to the levels of cell death detected by TUNEL staining in those lesions (Fig. 5c, L1-L4).

Lastly, with a view to clinical translation, we conducted optoacoustic imaging of cell death in the same DCIS model using C2Am and iC2Am. Six to 8 weeks post-orthotopic implantation of MCF10A $\mathrm{ACIS}_{\mathrm{S}}$ cells, an equimolar mixture of $\mathrm{C} 2 \mathrm{Am}$ and $\mathrm{iC} 2 \mathrm{Am}$ was injected (i.v.) and optoacoustic imaging (Fig. 6a, b) and FLI (Fig. 6c) were performed in vivo and ex vivo, respectively, at 4 and $24 \mathrm{~h}$ post-probe administration. There were strong correlations between C2Am lesion MSOT signal and cell death markers (Fig. 6d), CC3 (Fig. 6d, $R=0.973, P=$ 0.001), and TUNEL (Fig. 6d, $R=0.962, P=0.002$ ) and 


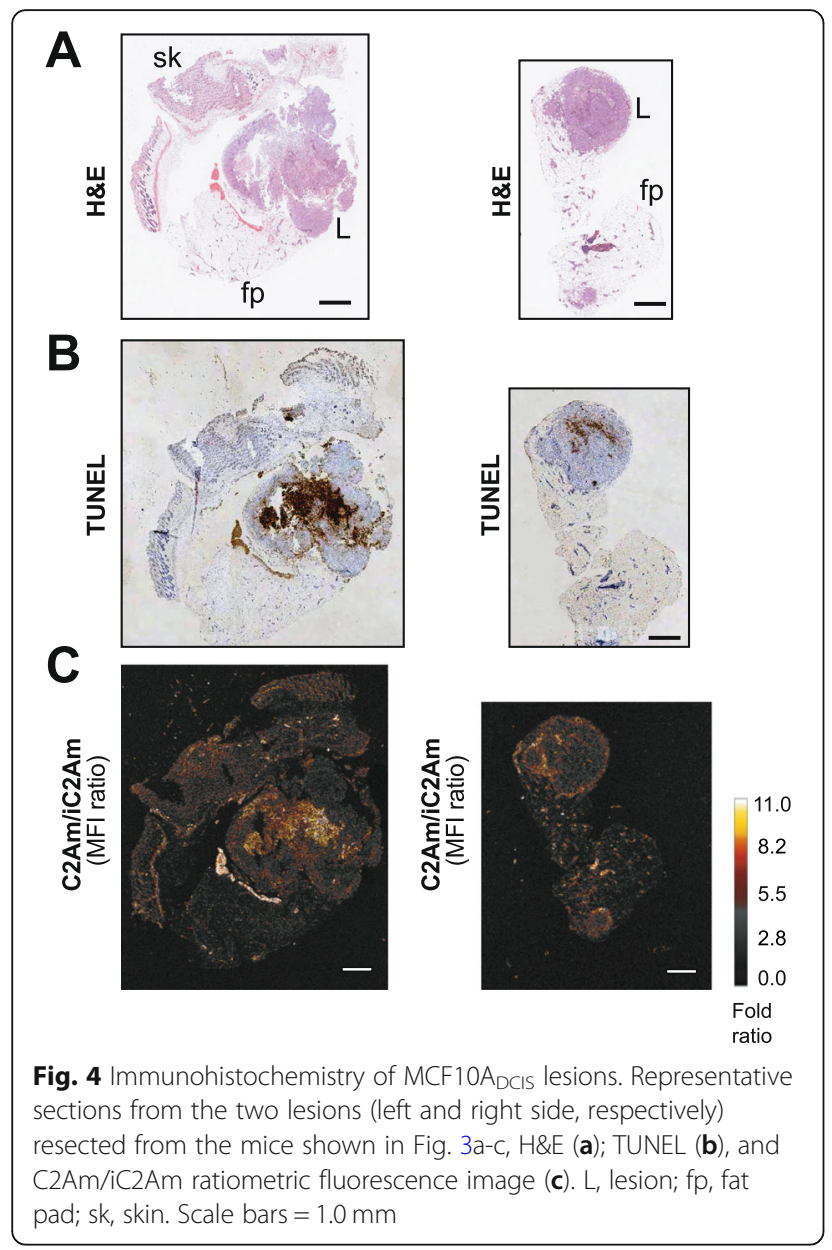

also between $\mathrm{C} 2 \mathrm{Am}$ lesion MSOT and FLI signals (Fig. 6d, $R=0.875, P=0.022$ ). iC2Am lesion MSOT and FLI signals (Fig. 6d) did not correlate with the cell death markers.

\section{Discussion}

Several cell surface markers have been proposed as targets for the molecular imaging of DCIS, including IGF1-R, VEGFr, HER2, EGFR, MET, CD44v6, GLUT1, CA-XII, and mammaglobin [35]. However, to date, none of these biomarkers has been generally adopted as a predictor of DCIS recurrence [36]. Fluorescence imaging of CA-IX, a marker of hypoxia, has been suggested for better delineation of DCIS margins at surgery [37]. However, hypoxia lacks specificity as a marker of DCIS, since it can be a feature of any highly proliferative process, either benign or malignant [38], particularly in breast ducts.

Molecular markers, including hormone receptors (estrogen or progesterone) and HER-2 expression status, have been used previously as imaging biomarkers of breast cancer [39, 40]. However, these breast cancer biomarkers have not been established as prognostic features of DCIS [41], despite their clinical relevance as prognostic factors in breast cancer [42]. In contrast, necrosis is a highly specific, pathognomonic feature of DCIS, present in up to $93 \%$ of all DCIS cases [38, 43] and rarely exhibited $(<3 \%)$ by other benign or high-risk proliferative conditions of the breast [44], and which has been used as a prognostic marker of DCIS for several decades [45]. The UKCCCR/ANZ DCIS trial demonstrated that not only the presence but also the anatomical extent of DCIS-associated necrosis are adverse prognostic features of the disease, and both are strong predictors of invasive recurrence [9]. Moreover, in a 10year follow-up study of 728 patients, the presence of confluent tumor necrosis in invasive areas of lymphnode positive breast cancer, within 2 years of diagnosis, was found to be an independent predictor for early recurrence and overall survival [46].

Owing to the significant concern of overdiagnosis and associated overtreatment, there are several ongoing clinical trials exploring treatment de-escalation in the management of DCIS [47, 48]. These trials compare active patient surveillance with the current standard of care (mandatory surgical excision) and have excluded patients with DCIS harboring adverse prognostic features, including the presence of comedo-necrosis at biopsy. However, reliable detection of comedo-type necrosis in biopsy specimens shows significant variability, even among expert pathologists [12]. Moreover, segments of DCIS containing the comedo sub-type can be potentially missed, since a single biopsy cannot be informative of the extent of DCIS present in the entire network of breast ducts. Approximately $10 \%$ of patients, deemed eligible as "low risk" DCIS for the ongoing COMET, LORD, and LORIS trials based on the initial diagnostic biopsy, have been estimated to belong to the "high-risk" group [9].

To our knowledge, the use of DCIS-associated necrosis as an imaging biomarker of the diseased breast has not yet been explored. Non-invasive molecular imaging of comedo-type necrosis could serve as an adjunct modality in the selection of patients for active surveillance. Moreover, it could also provide complementary prognostic information on the extent of aggressive, high-risk disease that cannot be obtained by biopsy.

Annexin-V $(35 \mathrm{kDa})$ is a PS-binding protein that has been tested in the clinic as a cell death imaging agent. However, it showed suboptimal contrast and unfavorable pharmacokinetics [49]. We have used here C2Am, a smaller $(16 \mathrm{kDa})$ cell death imaging agent, which also detects PS exposure, to detect comedo-type necrosis in DCIS in a well-characterized 
A
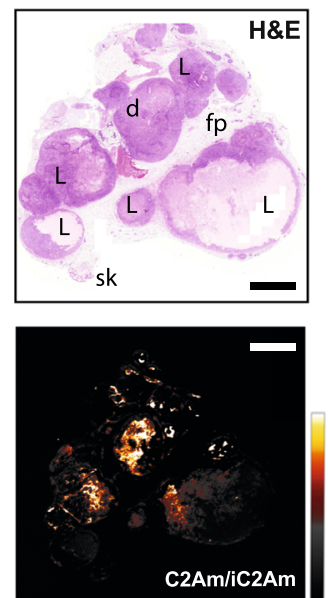

C2Am/iC2Am

B

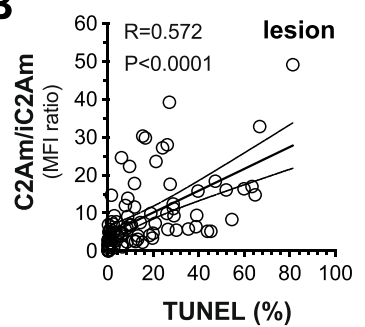

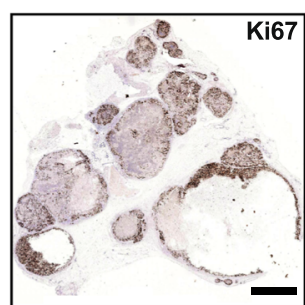
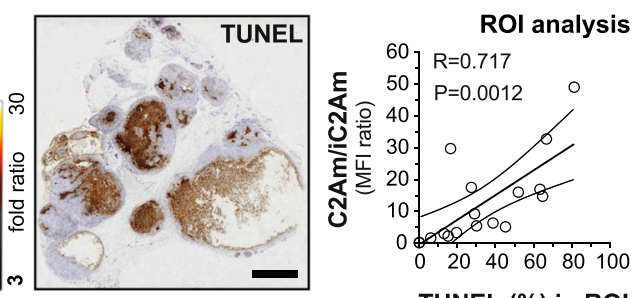

TUNEL (\%) in ROI
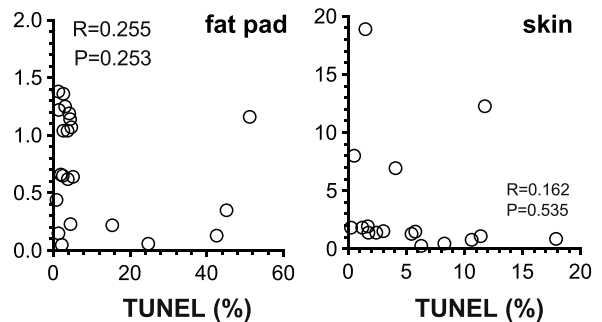

C
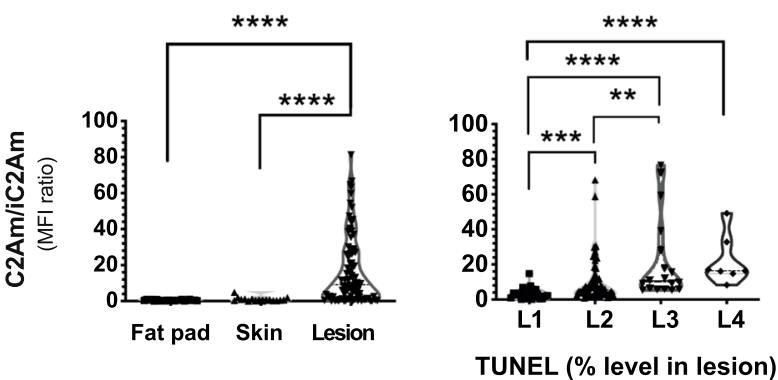

Fig. 5 Immunohistochemistry of MCF10A $A_{D C I S}$ lesions. Serial histological sections (a) of one representative MCF10A post-intraductal cell implantation. H\&E, Ki-67, CC3, TUNEL, and C2Am/iC2Am ratiometric fluorescence signals are shown. Chart (a), correlation of the C2Am/iC2Am ratiometric signal with the percentage of cell death, determined by TUNEL assay, for regions of interest (ROI) of the lesion shown in $\mathbf{a}$. L, lesion; fp, fat pad; sk, skin. Correlation of C2Am/iC2Am ratiometric signal (b) from multiple lesions, fat pad, and skins from several mice with the corresponding levels of TUNEL staining. C2Am/iC2Am ratiometric signal (c) in multiple fat pad, skin, and lesions. L1: < 10\% TUNEL positivity, L2: 10-25\%, L3: 25-50\%, L4: > 50\%. b, c, $n=10$ mice, 89 lesions, 22 fat pad, 17 skin samples. c Two-tailed, $t$ test, unequal variance. **P< $0.005,{ }^{* *} P<0.001,{ }^{* * * *} P<0.0001$. Scale bars $(\mathbf{a})=2 \mathrm{~mm}$

human-to-mouse xenograft model (Fig. 1). The probe was used in combination with an inactive counterpart (iC2Am) and showed high specificity for detecting cell death in vitro (Fig. 2), in vivo (Figs. 3 and 6), and ex vivo (Fig. 4). Moreover, C2Am demonstrated high sensitivity for detecting the relatively low levels of cell death present in MCF10A $_{\mathrm{DCIS}}$ lesions $(<5 \%)$ in vivo (Fig. 3g) and ex vivo (Fig. 4) and over a wide dynamic range (up to $20 \%$ in vivo, Fig. $3 g$, and up to $80 \%$ ex vivo, Fig. 5a). High levels of contrast were obtained for lesion/fat pad (30-fold) and lesion/skin (15- fold) (Fig. 5c, left), and the ratiometric $\mathrm{C} 2 \mathrm{Am} / \mathrm{iC} 2 \mathrm{Am}$ signal was shown to correlate with the levels of cell death (Fig. 5c, right) detected by TUNEL staining.

Recent reports using optoacoustic techniques have demonstrated the capabilities of the technique for breast imaging [18]. We showed that the signal obtained from C2Am (Fig. 6a, b) using multispectral optoacoustic tomography (MSOT) correlated well with that obtained using fluorescence imaging (Fig. 6c, top). Moreover, the C2Am MSOT signal also correlated well with histological markers of cell death, CC3, and TUNEL (Fig. 6d), 


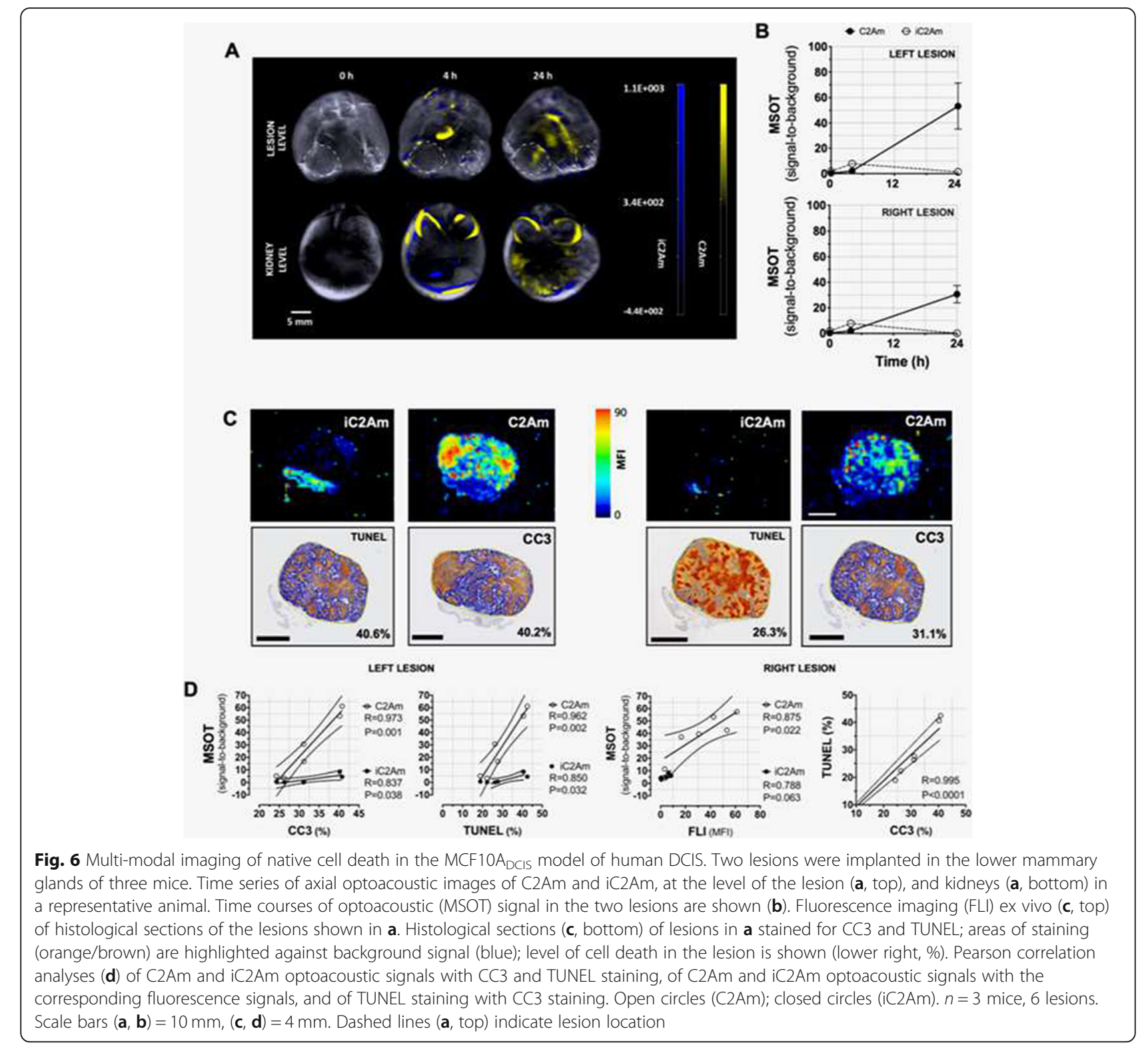

whereas iC2Am generated significantly less signal $(P<0.05, n=6)$ in the same lesions (Fig. 6d). Beyond wide-field epi-illumination fluorescence imaging, optoacoustic methods can offer high-resolution and cross-sectional imaging at several centimeters depth [17]. C2Am-based imaging of cell death using optoacoustic imaging could bring additional prognostic value to DCIS imaging, complementing mammography and other anatomical imaging modalities, which could prove particularly beneficial for the secondary surveillance of women with an increased risk of breast cancer [50]. Optoacoustic imaging is a bed-side technique that could provide a faster and cheaper diagnostic method than MRI.

\section{Conclusions}

Clinical translation of $\mathrm{C} 2 \mathrm{Am}$ for imaging the presence and spatial extent of necrosis in DCIS may provide valuable prognostic information that is not obtainable from biopsy alone.

\section{Supplementary Information}

The online version contains supplementary material available at https://doi. org/10.1186/s13058-021-01404-z.

Additional file 1: Figure $\mathbf{S 1}$ Fluorescence imaging (a) of C2Am and iC2Am standard solutions. Excitation (dashed) and emission (filled) profiles (b) of iC2Am-650 (EX/Em: 652|672 nm, red, left) and C2Am-750 (Ex/Em: $753 \mid 783 \mathrm{~nm}$, brown, right). Serial dilutions (decreasing concentration, left to right) of the imaging probes (c, e) were imaged on an 
IVIS200 ${ }^{\text {TM }}$ system and the mean fluorescence intensity (in radiant efficiency) correlated with probe concentration, in the far red (d) and near infra-red NIR (f), for C2Am (open circles) and iC2Am (closed squares). iC2Am fluorescence (d) in the far-red (black squares) was minimal (ca. $10 \%$ of that of C2Am, open circles). C2Am fluorescence (f) in the NIR was undetectable. Fluorescence intensities (g) of C2Am-650 (in the far-red, open circles in $\mathbf{g}$, data in 2nd row of $\mathbf{c}$ ) and iC2Am-750 (in the NIR, closed squares in $\mathbf{g}$, data in the top row of $\mathbf{e}$ ) were identical at all concentrations. A 1:1 molar mixture (h) of C2AmliC2Am (c, e, lower row) was also imaged in the far-red (open circles) and NIR (closed squares) showing equivalent readouts at all concentrations, in the range 40-2,500 nM. Figure S2. Single wavelength OA images of (a) phantoms (b) and in vivo tumor models are illustrated with the regions of interest (ROIs) used for the data analysis outlined. (c) OA spectra of iC2Am and C2Am molecules were obtained from multispectral imaging of the probes using tissue mimicking phantoms.

\section{Abbreviations}

BLI: Bioluminescence imaging; BCS: Breast-conserving surgery; CC3: Cleavedcaspase-3 histological assay for apoptosis; COMET: Comparison of Operative to Monitoring and Endocrine Therapy clinical trial; DCIS: Ductal carcinoma in situ; FLI: Planar fluorescence imaging; H\&E: Hematoxylin and eosin; LORD: LOw-Risk DCIS clinical trial; LORIS: LOw-RISk DCIS clinical trial; MCF10ADCIS: MCF10ADCIS.com breast cell line transfected with firefly luciferase and RFP; NIR: Near-infrared fluorescence imaging; OA: Optoacoustic imaging; PS: Phosphatidylserine; RFP: Red fluorescent protein;

TUNEL: Terminal deoxynucleotidyl transferase dUTP nick-end labeling histological assay for necrosis

\section{Acknowledgements}

ZS was the recipient of a Ph.D. studentship from the Cambridge Cancer Centre. We are grateful to the CRUK Cambridge Institute Histopathology, Imaging and Research Instrumentation Core Units, for their technical support.

\section{Authors' contributions}

$\mathrm{AAN}, \mathrm{ZS}$, and $\mathrm{KMB}$ conceived and designed the study. AAN, ZS, and JJ acquired, analyzed, and interpreted the data. JJ, SEB, and AAN developed the methodology. AAN, ZS, JJ, SEB, and KMB wrote the manuscript. BX and TJL provided technical and material support. AAN supervised the study. The authors read and approved the final manuscript.

\section{Funding}

This work was supported by a Cancer Research UK programme grant to KMB (17242) and by the CRUK-EPSRC Imaging Centre in Cambridge and Manchester (16465; KMB and SEB).

\section{Availability of data and materials}

The raw data acquired during this study and on which the results presented in this paper are based can be found at https://doi.org/10.17863/CAM.64395.

\section{Ethics approval and consent to participate}

Not applicable

\section{Consent for publication}

Not applicable

\section{Competing interests}

C2Am is under a licensing agreement with Cambridge Enterprise and has been patented (US2011/0038798). Some of the authors of this study (AAN and KMB) are co-inventors on this patent. No other potential conflict of interest relevant to this article was reported.

\section{Author details}

'Cancer Research UK Cambridge Institute, Li Ka Shing Centre, University of Cambridge, Robinson Way, Cambridge CB2 ORE, UK. ${ }^{2}$ Department of Physics, University of Cambridge, Cambridge, UK. ${ }^{3}$ Present address: University of Dundee, School of Science and Engineering, Dundee, UK. ${ }^{4}$ Department of Biochemistry, University of Cambridge, Cambridge, UK.
Received: 15 October 2020 Accepted: 1 February 2021

Published online: 17 February 2021

\section{References}

1. Siegel RL, Miller KD, Jemal A. Cancer statistics, 2019. CA Cancer J Clin. 2019; 69:7.

2. Morris E, Feig SA, Drexler M, Lehman C. Implications of overdiagnosis: impact on screening mammography practices. Popul Health Manag. 2015; 18(Suppl 1):S3.

3. Lauby-Secretan B, Scoccianti C, Loomis D, Benbrahim-Tallaa L, Bouvard V, Bianchini F, et al. Breast-cancer screening--viewpoint of the IARC Working Group. N Engl J Med. 2015;372:2353.

4. Shah C, Wobb J, Manyam B, Kundu N, Arthur D, Wazer D, et al. Management of ductal carcinoma in situ of the breast: a review. JAMA Oncol. 2016;2:1083.

5. Thomas J, Hanby A, Pinder SE, Ball G, Lawrence G, Maxwell A, et al. Adverse surgical outcomes in screen-detected ductal carcinoma in situ of the breast. Eur J Cancer. 2014;50:1880

6. Grimm LJ, Ryser MD, Partridge AH, Thompson AM, Thomas JS, Wesseling J, et al. Surgical upstaging rates for vacuum assisted biopsy proven DCIS: implications for active surveillance trials. Ann Surg Oncol. 2017;24:3534.

7. Marmot MG, Altman DG, Cameron DA, Dewar JA, Thompson SG, Wilcox M. The benefits and harms of breast cancer screening: an independent review. Br J Cancer. 2013;108:2205.

8. Zhang X, Dai H, Liu B, Song F, Chen K. Predictors for local invasive recurrence of ductal carcinoma in situ of the breast: a meta-analysis. Eur J Cancer Prev. 2015;25:19.

9. Pinder SE, Duggan C, Ellis IO, Cuzick J, Forbes JF, Bishop H, et al. A new pathological system for grading DCIS with improved prediction of local recurrence: results from the UKCCCR/ANZ DCIS trial. Br J Cancer. 2010;103:94.

10. Kanbayashi $\mathrm{C}$, Iwata $\mathrm{H}$. Current approach and future perspective for ductal carcinoma in situ of the breast. Jpn J Clin Oncol. 2017:47:671.

11. Mannu GS, Groen EJ, Wang Z, Schaapveld M, Lips EH, Chung M, et al. Reliability of preoperative breast biopsies showing ductal carcinoma in situ and implications for non-operative treatment: a cohort study. Breast Cancer Res Treat. 2019;178:409.

12. Harrison BT, Hwang ES, Partridge AH, Thompson AM, Schnitt SJ. Variability in diagnostic threshold for comedo necrosis among breast pathologists: implications for patient eligibility for active surveillance trials of ductal carcinoma in situ. Mod Pathol. 2019;32:1257.

13. Health QO. Magnetic resonance imaging as an adjunct to mammography for breast cancer screening in women at less than high risk for breast cancer: a health technology assessment. Ont Health Technol Assess Ser. 2016;16:1.

14. Fancellu A, Turner RM, Dixon JM, Pinna A, Cottu P, Houssami N. Metaanalysis of the effect of preoperative breast MRI on the surgical management of ductal carcinoma in situ. Br J Surg. 2015;102:883.

15. Geisel J, Raghu M, Hooley R. The role of ultrasound in breast cancer screening: the case for and against ultrasound. Semin Ultrasound CT MR. 2018;39:25.

16. Boyd NF. Mammographic density and risk of breast cancer. Am Soc Clin Oncol Educ Book. 2013. https://doi.org/10.1200/EdBook_AM.2013.33.e57.

17. Attia ABE, Balasundaram G, Moothanchery M, Dinish US, Bi R, Ntziachristos $\checkmark$, et al. A review of clinical photoacoustic imaging: current and future trends. Photoacoustics. 2019;16:100144.

18. Lin L, Hu P, Shi J, Appleton CM, Maslov K, Li L, et al. Single-breath-hold photoacoustic computed tomography of the breast. Nat Commun. 2018:9:2352.

19. Menezes GLG, Mann RM, Meeuwis C, Bisschops B, Veltman J, Lavin PT, et al. Optoacoustic imaging of the breast: correlation with histopathology and histopathologic biomarkers. Eur Radiol. 2019;29:6728.

20. Alam IS, Neves AA, Witney TH, Boren J, Brindle KM. Comparison of the C2A domain of Synaptotagmin-I and Annexin- $V$ as probes for detecting cell death. Bioconjug Chem. 2010;21:884.

21. Neves AA, Brindle KM. Imaging cell death. J Nucl Med. 2014;55:1.

22. Xie B, Tomaszewski MR, Neves AA, Ros S, Hu DE, McGuire S, et al. Optoacoustic detection of early therapy-induced tumor cell death using a targeted imaging agent. Clin Cancer Res. 2017;23:6893. 
23. Neves AA, Xie B, Fawcett S, Alam IS, Witney TH, de Backer MM, et al. Rapid imaging of tumor cell death in vivo using the C2A domain of Synaptotagmin-I. J Nucl Med. 2017;58:881.

24. Bulat F, Hesse F, Hu DE, Ros S, Willminton-Holmes C, Xie B, et al. ${ }^{18} \mathrm{~F}-\mathrm{C} 2 \mathrm{Am}$ : a targeted imaging agent for detecting tumor cell death in vivo using positron emission tomography. EJNMMI Res. 2020;10:151.

25. Behbod F, Kittrell FS, LaMarca H, Edwards D, Kerbawy S, Heestand JC, et al. An intraductal human-in-mouse transplantation model mimics the subtypes of ductal carcinoma in situ. Breast Cancer Res. 2009;11:R66.

26. Miller FR, Santner SJ, Tait L, Dawson PJ. MCF10DCIS.com xenograft model of human comedo ductal carcinoma in situ [letter]. J Natl Cancer Inst. 2000;92: 1185-6.

27. Barnabas N, Cohen D. Phenotypic and molecular characterization of MCF10DCIS and SUM breast cancer cell lines. Int J Breast Cancer. 2013;2013: 872743

28. Patrick PS, Hammersley J, Loizou L, Kettunen MI, Rodrigues TB, Hu DE, et al. Dual-modality gene reporter for in vivo imaging. Proc Natl Acad Sci U S A. 2014;111:415.

29. Workman P, Aboagye EO, Balkwill F, Balmain A, Bruder G, Chaplin DJ, et al. Guidelines for the welfare and use of animals in cancer research. $\mathrm{Br} J$ Cancer. 2010:102:1555.

30. Joseph J, Tomaszewski MR, Quiros-Gonzalez I, Weber J, Brunker J, Bohndiek SE. Evaluation of precision in optoacoustic tomography for preclinical imaging in living subjects. J Nucl Med. 2017;58:807.

31. Dima A, Burton NC, Ntziachristos V. Multispectral optoacoustic tomography at 64, 128, and 256 channels. J Biomed Opt. 2014;19:36021.

32. Hesketh RL, Wang J, Wright AJ, Lewis DY, Denton AE, Grenfell R, et al. Magnetic resonance imaging is more sensitive than PET for detecting treatment-induced cell death-dependent changes in glycolysis. Cancer Res. 2019;79:3557.

33. Miller FR, Soule HD, Tait L, Pauley RJ, Wolman SR, Dawson PJ, et al. Xenograft model of progressive human proliferative breast disease. J Natl Cancer Inst. 1993:85:1725.

34. Grabarek J, Amstad P, Darzynkiewicz Z. Use of fluorescently labeled caspase inhibitors as affinity labels to detect activated caspases. Hum Cell. 2002;15:1.

35. Vermeulen JF, van der Wall E, Witkamp AJ, van Diest PJ. Analysis of expression of membrane-bound tumor markers in ductal carcinoma in situ of the breast: paving the way for molecular imaging. Cell Oncol (Dordr). 2013;36:333.

36. Benson JR, Wishart GC. Predictors of recurrence for ductal carcinoma in situ after breast-conserving surgery. Lancet Oncol. 2013;14:e348.

37. van Brussel AS, Adams A, Vermeulen JF, Oliveira S, van der Wall E, Mali WP, et al. Molecular imaging with a fluorescent antibody targeting carbonic anhydrase IX can successfully detect hypoxic ductal carcinoma in situ of the breast. Breast Cancer Res Treat. 2013;140:263.

38. Bussolati G, Bongiovanni M, Cassoni P, Sapino A. Assessment of necrosis and hypoxia in ductal carcinoma in situ of the breast: basis for a new classification. Virchows Arch. 2000;437:360

39. van Kruchten M, de Vries EGE, Brown M, de Vries EFJ, Glaudemans AWJM, Dierckx RAJO, et al. PET imaging of oestrogen receptors in patients with breast cancer. Lancet Oncol. 2013;14:e465.

40. van Kruchten M, de Vries EF, Arts HJ, Jager NM, Bongaerts AH, Glaudemans AW, et al. Assessment of estrogen receptor expression in epithelial ovarian cancer patients using 16a-18F-fluoro-17ß-estradiol PET/CT. J Nucl Med. 2015;56:50.

41. Hammond ME, Hayes DF, Dowsett M, Allred DC, Hagerty KL, Badve S, et al. American Society of Clinical Oncology/College of American Pathologists guideline recommendations for immunohistochemical testing of estrogen and progesterone receptors in breast cancer. Arch Pathol Lab Med. 2010;134:907.

42. Nofech-Mozes S, Spayne J, Rakovitch E, Hanna W. Prognostic and predictive molecular markers in DCIS: a review. Adv Anat Pathol. 2005;12:256.

43. Virnig BA, Tuttle TM, Shamliyan T, Kane RL. Ductal carcinoma in situ of the breast: a systematic review of incidence, treatment, and outcomes. J Natl Cancer Inst. 2010;102:170.

44. Harris JR, Lippman ME, Morrow MM, Osborne CK. Diseases of the breast. Philadelphia: Wolters Kluwer Health Adis (ESP); 2014

45. Silverstein MJ, Poller DN, Waisman JR, Colburn WJ, Barth A, Gierson ED, et al. Prognostic classification of breast ductal carcinoma-in-situ. Lancet. 1995;345:1154.

46. Gilchrist KW, Gray R, Fowble B, Tormey DC, Taylor SG. Tumor necrosis is a prognostic predictor for early recurrence and death in lymph node-positive breast cancer: a 10-year follow-up study of 728 Eastern Cooperative Oncology Group patients. J Clin Oncol. 1993;11:1929.

47. Pilewskie M, Stempel M, Rosenfeld H, Eaton A, Van Zee KJ, Morrow M. Do LORIS trial eligibility criteria identify a ductal carcinoma in situ patient population at low risk of upgrade to invasive carcinoma. Ann Surg Oncol. 2016;23:3487.

48. Elshof LE, Tryfonidis K, Slaets L, van Leeuwen-Stok AE, Skinner VP, Dif N, et al. Feasibility of a prospective, randomised, open-label, international multicentre, phase III, non-inferiority trial to assess the safety of active surveillance for low risk ductal carcinoma in situ - The LORD study. Eur J Cancer. 2015;51:1497.

49. Morgan MP, Cooke MM, McCarthy GM. Microcalcifications associated with breast cancer: an epiphenomenon or biologically significant feature of selected tumors? J Mammary Gland Biol Neoplasia. 2005;10:181.

50. Boyd NF, Guo H, Martin LJ, Sun L, Stone J, Fishell E, et al. Mammographic density and the risk and detection of breast cancer. N Engl J Med. 2007;356: 227.

\section{Publisher's Note}

Springer Nature remains neutral with regard to jurisdictional claims in published maps and institutional affiliations.
Ready to submit your research? Choose BMC and benefit from:

- fast, convenient online submission

- thorough peer review by experienced researchers in your field

- rapid publication on acceptance

- support for research data, including large and complex data types

- gold Open Access which fosters wider collaboration and increased citations

- maximum visibility for your research: over $100 \mathrm{M}$ website views per year

At $\mathrm{BMC}$, research is always in progress.

Learn more biomedcentral.com/submissions 